\title{
Effects of Soil Water Content in Four Soybean Genotypes in Different Environments in the Central Area of the Argentine Pampean Region
}

\author{
Martín M. Silva Rossi ${ }^{1}$, Gabriel C. Caterina ${ }^{2}$, Rodolfo L. Rossi ${ }^{3}$ \\ ${ }^{1}$ Agricultural Study, Venado Tuerto, Argentina \\ ${ }^{2}$ Freelance Advisor, Venado Tuerto, Argentina \\ ${ }^{3}$ Nidera Grains, Venado Tuerto, Argentina \\ Email:info@eagronomico.com.ar
}

Received 15 October 2015; accepted 31 October 2015; published 5 November 2015

Copyright (C) 2015 by authors and OALib.

This work is licensed under the Creative Commons Attribution International License (CC BY). http://creativecommons.org/licenses/by/4.0/

\section{(c) (i) Open Access}

\section{Abstract}

In the Pampa Region there is limited information about the dynamics of soil water and the consumption rate of different soybean genotypes. In the Pampa Central Area, the first $15 \mathrm{~cm}$ of soil concentrates $80 \%$ of the soybean plant's root weight and over $40 \%$ of root absorbent surface. Despite the importance of extracting the first centimeters of water, the water supply in deeper zones could be very important as well. Because of this fact, the evaluation of the evolution of soil moisture was proposed: in two soil types-Typic Hapludoll and Entic Hapludoll; in different climatic years; in four soybean genotypes-NA 3731RG, NA 4209RG, NA 4613RG and NA 5009RG; in their effect on crop yield. In each of these environments, soil water content measurements were made in the first $100 \mathrm{~cm}$ with a TDR (Total Dormain Reflectometry) drill, over varietal performance tests with three replications per genotype in each location. In all evaluated situations, a significant effect on interaction genotype $x$ soil depth, genotype $x$ crop emergence days and crop emergence days $x$ soil depth was established. Also a fast development of roots was observed, having found active roots for the absorption of water within the first meter of depth 24 days after crop emergence. A difference in difference of radical elongation rate among varieties was also observed; because of the low water availability in vegetative phases with similar soil humidity distribution, the genotype NA 5009 RG had reached $20 \mathrm{~cm}$ more of radical activity faster than NA 4613RG. The highest crop yields were not associated to higher water content in soil during the whole cycle. Highest crop yields were associated to a combination of genotype, water availability between $50 \%$ of useful water during the whole vegetative cycle and the beginning of the flowering period, and high water availability in the first centimeters during reproductive phases. Under less water availability, the genotype with higher speed of radical deepening reached the highest yields. 


\title{
Keywords
}

\author{
Soybean, Water, Availability, Activity
}

Subject Area: Environmental Sciences

\section{Introduction}

It is crucial to know soil water content or soil humidity to explain a series of different processes: water balance, infiltration rates, crop growth and development (Bergkamp, 1996 [1]; Fitzjohn et al., 1998 [2]; Gómez Plaza, 2000 [3]). Since the late 1960s Bertolini et al., 1990 [4] start using time domain reflectometry technique for moisture measurements.

This technique is the most widely used in recent years to measure soil moisture, displacing the traditional methods based on gravimetric determination, neutron probe, electrical resistance, etc. The TDR offers several advantages: speed measurement, data in one place which avoids the error by spatial variability, possibility of profile soil moisture at different points of depth, high precision measurement and little impact on soil, and nondestructive sampling method on soil structure (Dalton, 1992 [5]).

High or low water content can reduce plant growth (García et al., 2008 [6]). Excess of water in soil reduces oxygen content affecting nutrient uptake, so plants show growth rate reduction, mainly on the radical system (Mendoza et al., 2005 [7]).

In Argentina Pampa Region, there is limited information about the dynamics of soil water and the consumption rate of different soybean genotypes (Dardanelli et al., 1991 [8]). In the performed studies, emphasis has been placed on differences caused by diverse management systems (Bonel et al., 2005 [9]). Other researchers (Ateca et al., 2001 [10]) have observed, in Córdoba Province, significant differences in water consumption rate due to the environment in which they have developed.

In the South of Santa Fe, according to Bonel et al. 2005 [9], 80\% of the soybean plant roots weight and over $40 \%$ of its absorbent surface are concentrated in the first $15 \mathrm{~cm}$ of soil. In these situations, researchers observed that soil humidity evolution in these first centimeters could have satisfied only a soybean crop demand less than 5 or $7 \mathrm{~mm} \cdot \mathrm{d}^{-1}$ of potential evapotranspiration (ETP) according to the climatic year. Despite the importance of water absorption within the first centimeters, availability in deeper layers may be important. Pantaleone et al., 1999 [11] studied the importance of the length and depth of the radical system and set differences in root length among soybean genotypes as indicators of potential capacity of water and nutrients absorption. Delgado et al., 2008 [12] concluded that an extensive radical system contributed to increasing biological nitrogen fixation since it provided a larger surface for nodulation.

Traditionally, rooting patterns have been analyzed by root weight density or root length density. These measuring methods are complex and need a lot of time, mainly in field conditions, since distributions vary with different plant species, soils, crop phenological stages, weather conditions and other factors (Besharat et al., 2009 [13]).

Further to these antecedents, the aim is to assess the evolution of soil water content and water consumption depth in four genotypes in two locations in southern Santa Fe Province over two crop years.

\section{Materials and Methods}

This experimental research was performed on two soil types according to Soil Taxonomy Typic Hapludoll (Venado Tuerto, Santa Fe) $33^{\circ} 45^{\prime} 036$ south latitude, 62 $02^{\circ} 812$ west longitude, Entic Hapludoll (Sancti Spirit, Santa $\mathrm{Fe}) 34^{\circ} 01^{\prime} 045$ south latitude, $62^{\circ} 13^{\prime} 101$ west longitude, that belong to surveys about varieties of Seed Company Nidera Argentina. These assessments were performed in two meteorologically different years: 2008 and 2009 .

Due to the different meteorological conditions recorded in soil humidity contents and distribution in both years and experimental sites, they are classified into four environmental conditions, resulting from the soil type and year. Therefore, four agroclimatic environments arise and are named: VT 2008, VT 2009, SS 2008 and SS 2009 (TypicHapludoll, EnticHapludoll; 2008 and 2009 year, located in the cities of Venado Tuerto and Sancti Spirit, Santa Fe State, Argentina, respectively). In each of the sites, in experimental plots with NA 3731, NA 4209, NA 
4613 and NA 5009 genotypes, PVC tubes were inserted alongside the crop line at regular intervals. Every five days, evolution of the soil water content was measured in up to 1-metre-depth, in 10cmranges, by using a TDR (Total Domain Reflectometry) drill. For each one of the genotypes, three repetitions were evaluated in Venado Tuerto and two repetitions in Sancti Spirit in each of the years.

In different environments, depth of radical activity was estimated by comparing how soil humidity contents varied in different crop stages.

Soil samples were extracted to determine the theoretical water constants, field capacity and permanent wilting points at 0.3 and 15 suction pressures through Richards Pressure Cooker (ASTM, 2003 [14]). The difference between 0.3 and 15 bars estimates the amount of available water (AW). The amount of water in excess of $50 \%$ of this range is more available to crops.

Results were analyzed by using ANOVA and differences among the averages compared with multiple comparison test, Fisher MCT, multivariate cluster analysis of generalized linear mixed models with InfoStat (Di Rienzo et al., 2010 [15]).

\section{Results and Discussion}

\subsection{Rains and Soil Properties}

Rains recorded in each of the cities and years, during crop cycle, are shown in Table 1.

In both sites during the two campaigns, rainfalls that took place during the crop cycle were significantly different. These differences were more significant in December and January.

Forecasts of the field capacity points, permanent wilting points and $50 \%$ of useful water are shown in Table 2 .

Table 1. Monthly rains in each of the experimental sites for both years.

\begin{tabular}{ccccccc}
\hline Site & Year & December & January & February & March & Total \\
\hline VT & 2008 & 171 & 110 & 226 & 79 & 586 \\
& 2009 & 70 & 44 & 161 & 72 & 347 \\
SS & 2008 & 81 & 127 & 130 & 70 & 408 \\
& 2009 & 49 & 37 & 163 & 44 & 293 \\
\hline
\end{tabular}

\begin{tabular}{|c|c|c|c|c|c|c|}
\hline \multirow{2}{*}{ Depth (cm) } & \multicolumn{3}{|c|}{ Typic Haplodull (VT) } & \multicolumn{3}{|c|}{ Entic Haplodull (SS) } \\
\hline & -0.3 Bars & -15 Bars & $50 \% \mathrm{UW}$ & -0.3 Bars & -15 Bars & $50 \%$ UW \\
\hline 10 & 30 & 13 & 21 & 24 & 10 & 17 \\
\hline 20 & 29 & 12 & 21 & 23 & 9 & 16 \\
\hline 30 & 29 & 12 & 20 & 23 & 9 & 16 \\
\hline 40 & 28 & 12 & 20 & 22 & 9 & 15 \\
\hline 50 & 28 & 12 & 20 & 21 & 9 & 15 \\
\hline 60 & 26 & 11 & 19 & 21 & 8 & 14 \\
\hline 70 & 26 & 11 & 18 & 20 & 8 & 14 \\
\hline 80 & 25 & 10 & 18 & 19 & 8 & 13 \\
\hline 90 & 24 & 10 & 17 & 19 & 8 & 13 \\
\hline 100 & 24 & 10 & 17 & 19 & 8 & 13 \\
\hline
\end{tabular}




\subsection{Yields}

In both sites, both years showed significantly different yields, as a result of genotype/environment interaction. Consequently, four previously established agro-climatic environments were differentiated into six productive environments. These environments are set into different groups by performing a cluster analysis (Figure 1).

As shown in Figure 1, Venado Tuerto environments outpaced Sancti Spirit and, only in 2008/2009 year, NA 5009 variety in Venado Tuerto showed similar behavior to Sancti Spirit and in conformity with NA 4613 and NA 4209 in this year and sites. In this site, NA 3731 variety of 2008-2009 year showed similar behavior to the most prominent variety of the previous year.

\subsection{Soil Humidity}

Information provided by soil moisture measurements in both sites and both years cannot be analyzed with standard statistical methods, due to lack of homogeneity of variance. The solution was to use Linear Mixed Models (LMM). With this information obtained from measurements, different models were adjusted. Afterwards, results were studied, based on predicted values by the best adjusted model, further to Akaike criterion (Zuur et al., 2009 [16]). Results from the studied models are shown in Table 3.

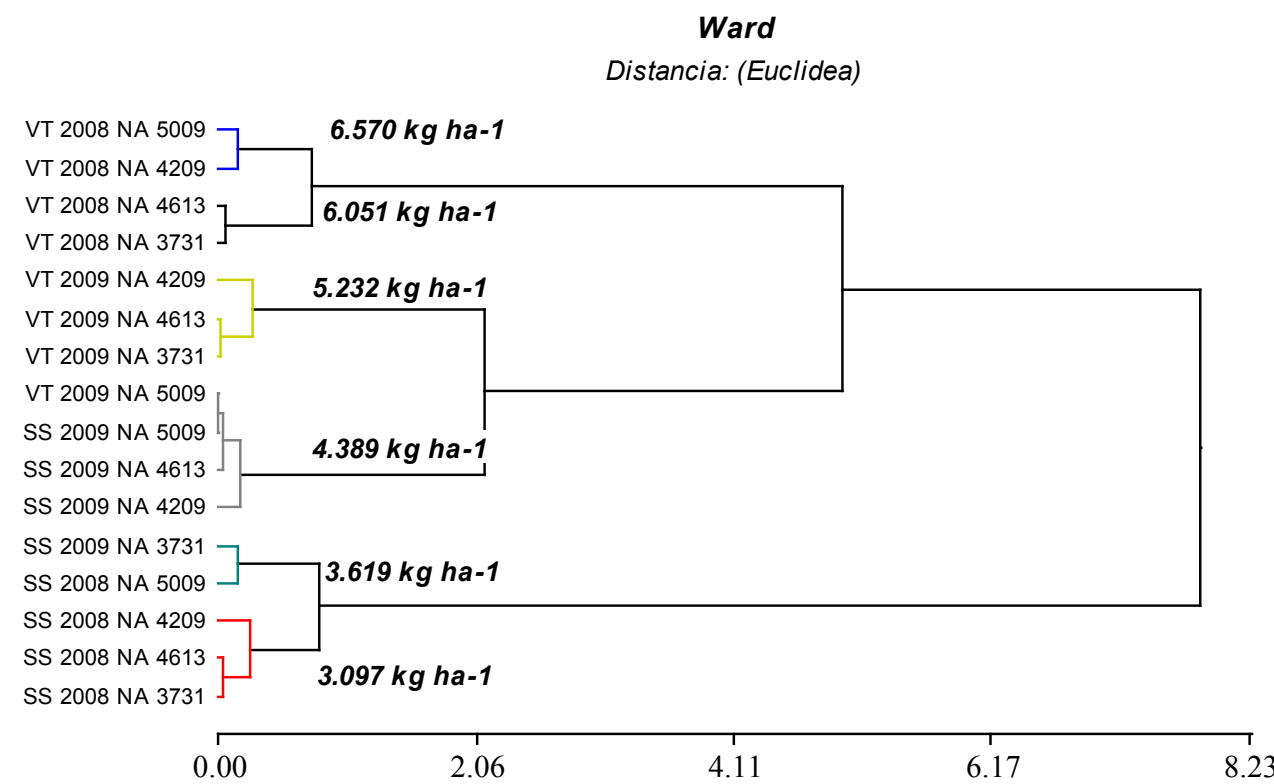

Figure 1. Cluster analysis to show yield from four soybean varieties within two years in two experimental sites (SS: Sancti Spirit; VT: Venado Tuerto).

Table 3. Significance level for different sources of variation and interactions in different agro climatic environments.

\begin{tabular}{|c|c|c|c|c|}
\hline \multirow{2}{*}{ Source of Variation } & \multicolumn{4}{|c|}{ Agro Climatic Environments and P-Value } \\
\hline & VT 2008 & SS 2008 & VT 2009 & SS 2009 \\
\hline Genotype & $<0.0001$ & $<0.0001$ & $<0.0001$ & $<0.0001$ \\
\hline Emergence days & $<0.0001$ & $<0.0001$ & $<0.0001$ & $<0.0001$ \\
\hline Water in depth & $<0.0001$ & $<0.0001$ & $<0.0001$ & $<0.0001$ \\
\hline Genotype * emergence days & 0.002 & 0.997 & 1.00 & 0.552 \\
\hline Genotype * water in depth & $<0.0001$ & $<0.0001$ & $<0.0001$ & $<0.0001$ \\
\hline Emergence days $*$ water in depth & $<0.0001$ & $<0.0001$ & $<0.0001$ & $<0.0001$ \\
\hline Genotype $*$ emergence days $*$ water in depth & 1.00 & 1.00 & 1.00 & 1.00 \\
\hline
\end{tabular}


Soil humidity measurements were performed regularly; on average, every five days during crop cycle. In this study, it is only shown measurements performed in each assessed soybean genotype at two specific time points during the vegetative period and at five time samples of the reproductive period.

In all tested environments, an interaction effect between soybean genotype and humidity variation with soil depth is observed, as well as between the timing and depth of measurement. Agronomically first interaction effect is important because it indicates that in the same location and year, the distribution of soil moisture in the soil profile was not similar in all genotypes, which resulted in differences in the depth of radical activity.

In Figure 2, variations in soil water content in vegetative stage and in the two reproductive stages that are critical for yield achievement for NA 4613 genotype in each year and sites are observed.

In Figure 2, one observes in Sancti Spirit Entic Hapludoll soil, that NA 4613 variety has, on the first stages of the vegetative cycle, water availability of around $50 \%$ of useful water. At the beginning of the flowering period (R2), crop has consumed water soil up to one-meter depth and a recharge is observed on the first $40 \mathrm{~cm}$ of soil profile. In grain fill, crop consumes water up to one-meter depth or deeper where it reaches values that are very close to permanent wilting point. In this very same soil, in the following year, crop starts its cycle in similar hydrous conditions, around $50 \%$ of useful water in the entire soil profile. Low rains that took place in December and January (Table 1) determined a higher consumption of the initial water reservoir up to one-meter depth in R2, reaching permanent wilting point below $50 \mathrm{~cm}$-depth. Rainfall occurred in February were not enough for water reservoir to recover; only availability of the first $40 \mathrm{~cm}$-depth was modified due to high consumption rates in R5 period.

In Venado Tuerto Typic Hapludoll soil, in 2008, this genotype started vegetative phase with water availability similar to Sancti Spirit, around 50\% of useful water in the first $100 \mathrm{~cm}$-depth. Rains registered in December and January did not modify water content and their distribution on the profile in R2 and V3. Root activity could be identified up to one meter depth. Up to R5, higher rains produced recharge of the soil profile. A radical system developed in depth could take advantage of this, and so, generated high yields (Figure 1). In this soil, the water conditions of 2009, changed considerably. In the first $50 \mathrm{~cm}$ of water availability, about $50 \%$ of its holding capacity and depth to free water due to the presence of a phreatic level at $150 \mathrm{~cm}$-depth was found. Low rainfall that took place in December and January favored water consumption in the entire profile; rainfall registered in grain fill only affected first $60 \mathrm{~cm}$ depth. Despite high water availability observed during the whole crop cycle, yield was lower than in the previous year (Figure 1).
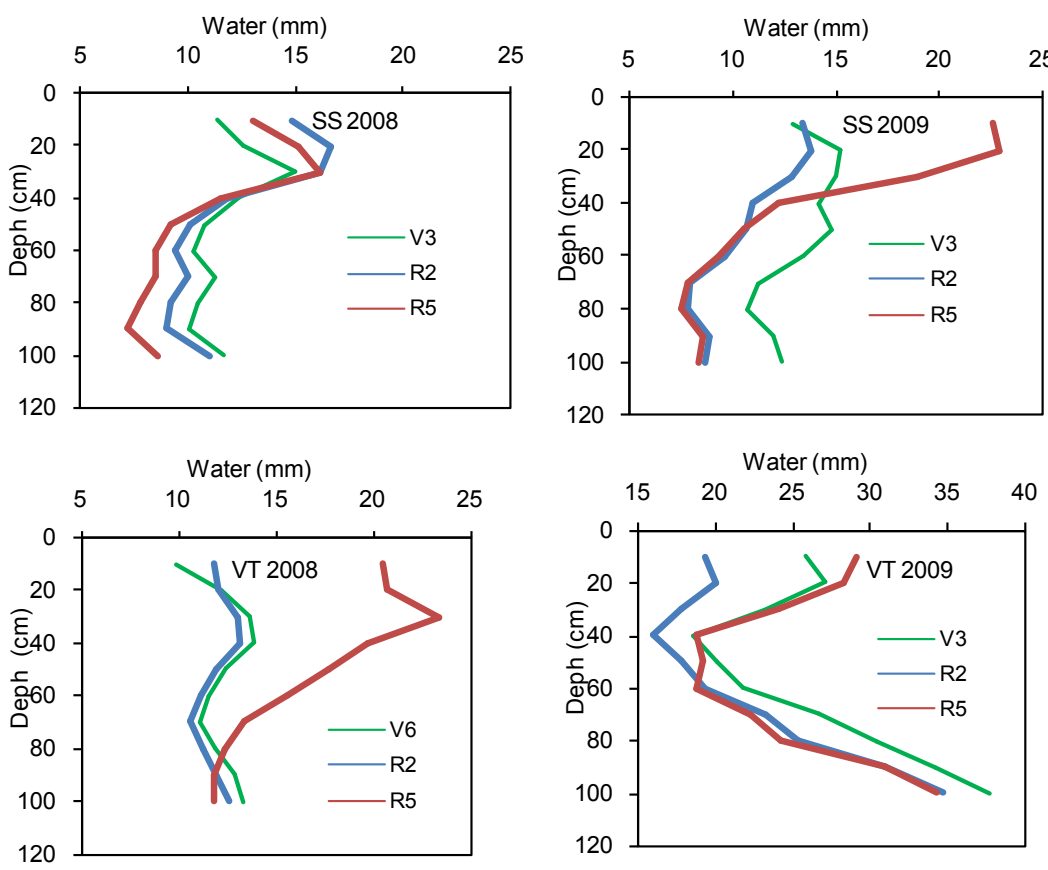

Figure 2. Predicted means values water content from 0 to $100 \mathrm{~cm}$ for NA 4613 variety, in two years and two agro climatic environments for genotype * depth. 
Figure 3 shows the variations in depth in water availability in two years and one location in genotype NA 3731.

In Sancti Spirit, the water distribution on soil profile in genotype NA 4613 is similar for both years. The only difference observed was in R5 in 2009, where the first $40 \mathrm{~cm}$ of water availability was higher with NA 4613 than with NA 3731, which could explain the higher yields (Figure 1).

In Venado Tuertoin 2008 and with NA 3731 genotype, increased water consumption was observed up to 100 $\mathrm{cm}$ in the period between V3 and R2 regarding NA 4613, then a greater recovery of water content occurred in R5. This increased water availability did not generate differences in yield. In 2009, conditions similar to those of NA 1613 were noticed but water consumption up to R5 was observed below $60 \mathrm{~cm}$ without distinguishing yield differences between genotypes for both years. In Figure 4, these variations for NA 4209 are observed.

In Sancti Spirit 2008, a water distribution pattern that is similar to that of previous varieties was observed. No difference in yield was observed. In 2009 up to R2, water distribution at one meter depth was similar to that of previous varieties. In R5, on the first 40cmdepth, February rainfall produced a higher recharge of water in this variety and NA 4613, and both were greater than NA 3731. NA 4209 and NA 4613 yields are similar and higher than NA 3731.

In Venado Tuerto, in 2008 up to R2, the availability of water to a meter in depth was found below $50 \%$ of available water. Water consumption in depth indicated a high rate of root growth. With rainfall in February, availability of water was recovered to $80 \mathrm{~cm}$ as in previous varieties. The yield of variety NA 4209 was higher than NA 3731 and NA 4613. In 2009, this variety had a higher availability of water to $100 \mathrm{~cm}$ depth. In R2, consumption was observed at a depth of one meter maintaining availability throughout the cycle with values higher than $75 \%$ of available water. This increased availability did not generate a higher yield. In Figure 5, these variations for NA 5009 variety are observed.

In Sancti Spirit, in 2008, a water distribution pattern that is similar to that of previous varieties is observed. Yield was higher than the previous three varieties. In 2009, up to R2, water distribution in one meter depth is similar to previous varieties. In R5, on the first $40 \mathrm{cmdepth}$, February rains produced a higher recharge of water in this variety, similar to the one for NA 4613 and NA 4209 varieties and higher than NA 3731. NA 5009, NA 4613 and NA 4209 yields were equal to each other and higher than NA 3731.

In Venado Tuerto, in 2008 up to R2, the water availability up to one meter depth was below $50 \%$ of water available, shown in the varieties analyzed above.
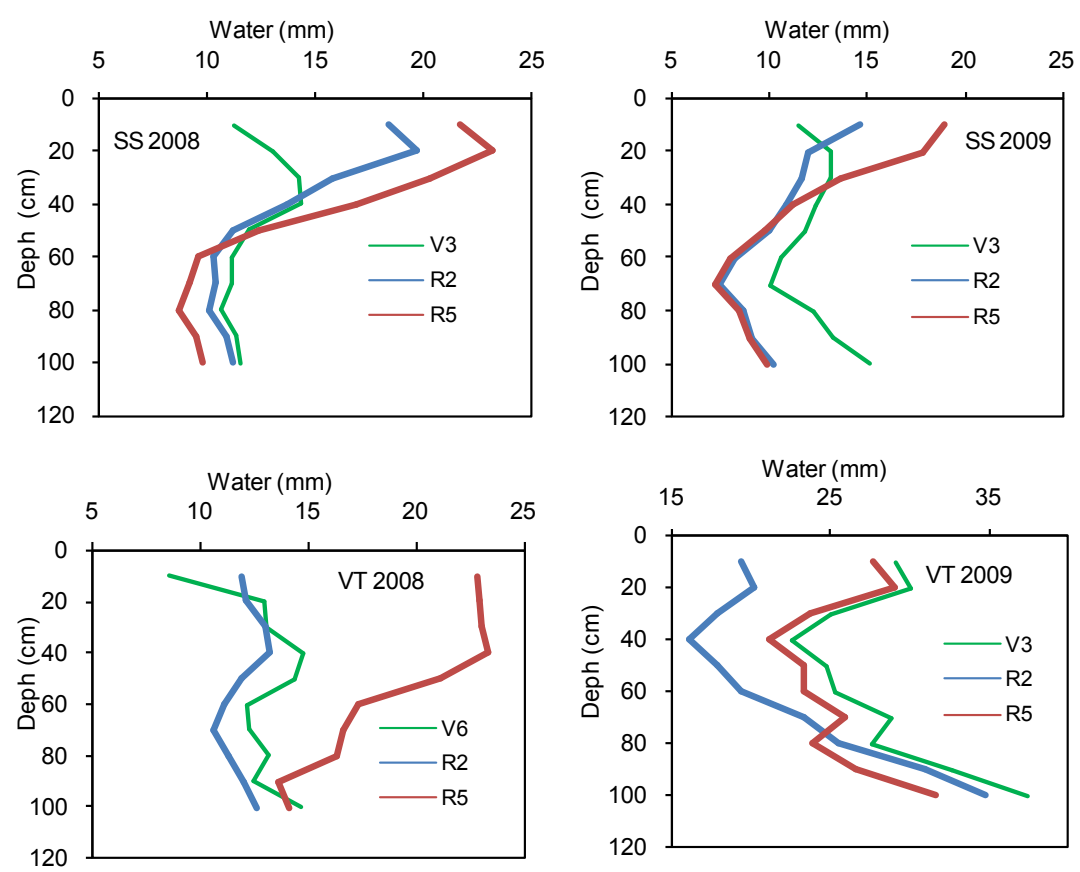

Figure 3. Variation in soil water content from 0 to $100 \mathrm{~cm}$ for NA 3731 variety within two years and two agro climatic environments. 

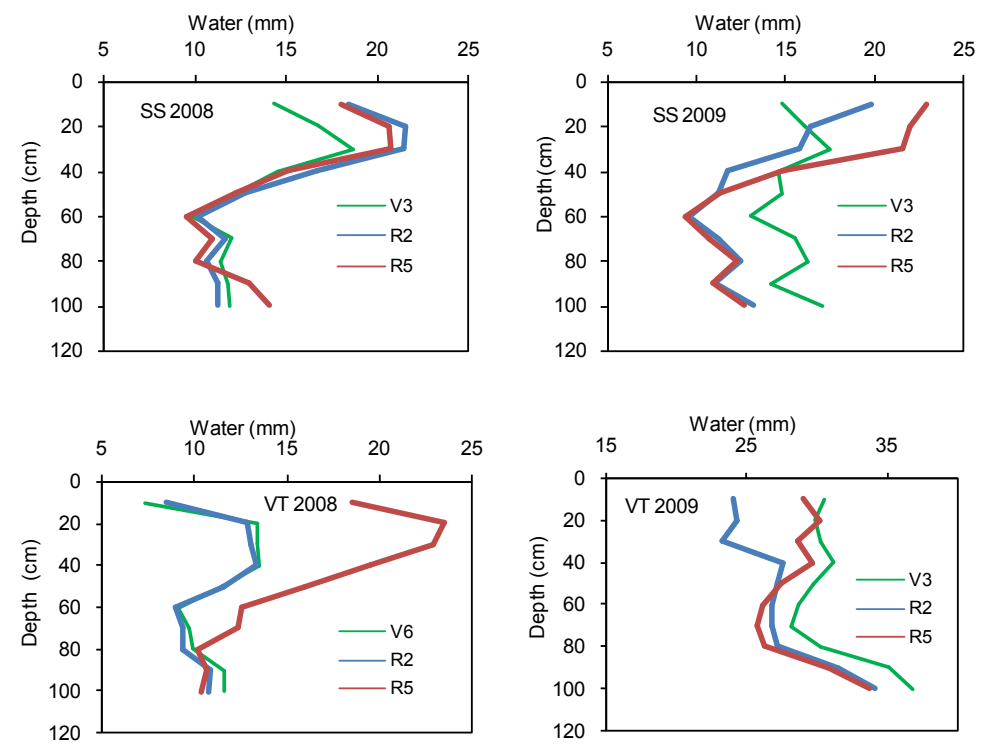

Figure 4. Variation in soil water content from 0 to $100 \mathrm{~cm}$ for NA 4209 variety in two agricultural years and two agro climatic environments.
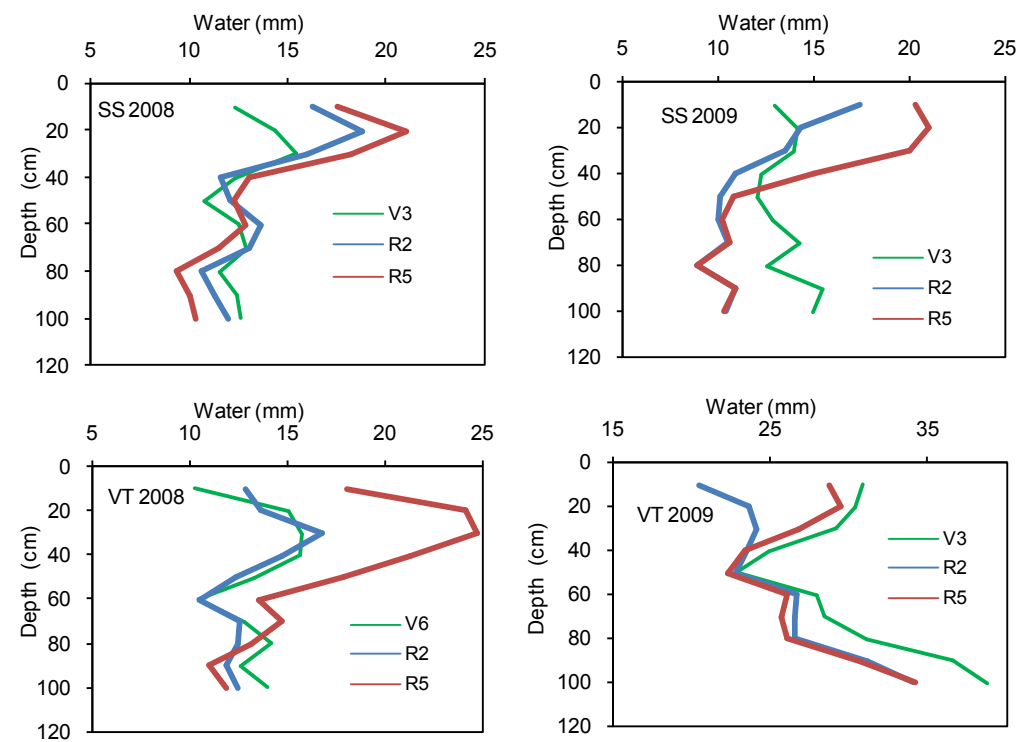

Figure 5. Variation in soil water content from 0 to $100 \mathrm{~cm}$ for NA 5009 variety within two agricultural years and two sites agro climatic environments.

The water consumption in depth indicates a high rate of root growth within the analyzed periods. With rainfall in February, the water availability recovers up to $80 \mathrm{~cm}$. In NA 5009 yield is equal to NA 4209 and greater than NA 4613 and NA 3713. In 2009, this variety has a similar availability of water up to $100 \mathrm{~cm}$ and the NA 4209 and higher than NA 4613 and NA 3731. In R2, consumption is observed in up to one meter depth, remaining availability throughout the cycle in excess of $75 \%$ of available water values. This condition of high water availability is manifested in a lower yield compared to other varieties. In environments where cultivation began its cycle with uniform water availability throughout the profile around $50 \%$ of available water values, a fast radical elongation is observed, which was estimated by the activity of the roots through decrease in soil water tenors in two successive times. Through these differences between genotypes in the initial rate of radical elongation (Figure 6), it was observed that the NA 5009 range at 20 days of emergence had active roots at $80 \mathrm{~cm}$ depth and variety NA 4613 was determined, only up to $60 \mathrm{~cm}$. 

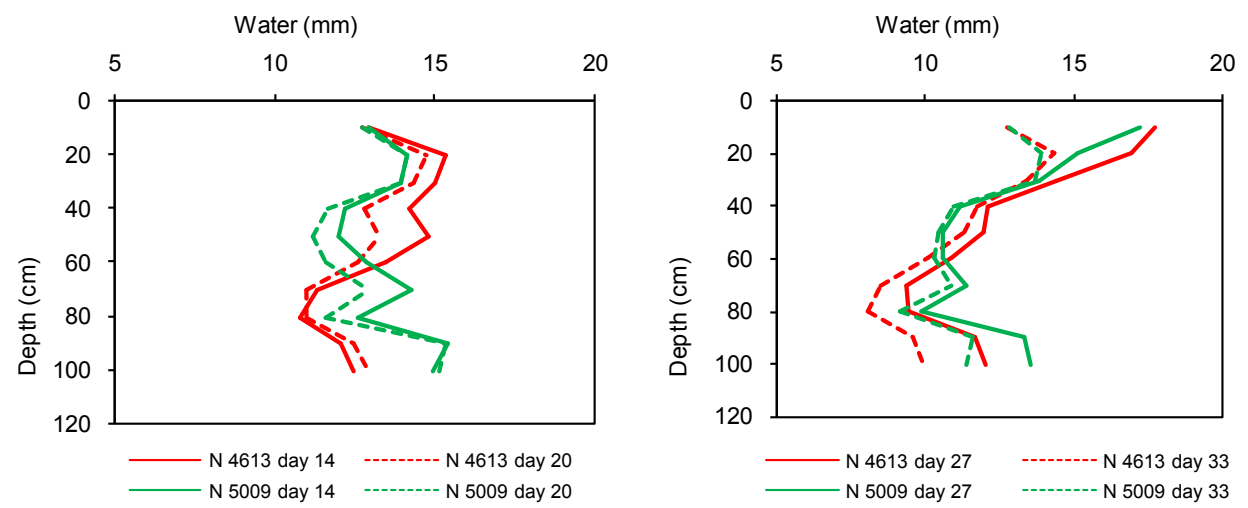

Figure 6. Differences in radical activity depth, 20 and 33 days after emergence, between varieties NA 5009 and NA 4613, growing in agro climatic environment SS 2009.

These differences in radical activity depth disappear 33 days after the crop emergence (Figure 6). At this stage, both varieties have roots that are active for water absorption bellow $100 \mathrm{~cm}$ depth. This indirect measurement, of radical activity depth, doesn't allow determining if there exist differences in root density among different soybean genotypes.

\section{Conclusions}

The results of the research show the effect of genotype/environment interaction, with soil type and climatic year defined as environment determining the distinguishing behavior of varieties.

Higher crop yields were observed in those situations where water availability was not high during vegetative stage, but evenly distributed in the entire soil profile. These conditions promoted a rapid development of the root system, which could take advantage of the available water at different depths. The occurrence of rainfall in the grain fill period recovered water availability in the profile and could be used by the crop at times of high water demand. In other conditions with greater water availability throughout the crop cycle and influence of a shallow phreatic level, yields did not reach their maximum value, probably developing a shallower root system which might have limited the absorption of water and/or nutrients in short periods. This happened due to water stress. This occurred after higher values of rainfall, where the field capacity point was reached in much of the profile, affecting the availability of oxygen and nutrients.

In several situations, a genotype/water depth interaction effect was observed, in some situations positive and one case negative. In Sancti Spirit in 2009, the NA 4209, NA 4613 and NA 5009 varieties showed a positive effect for this interaction, which was evidenced in increased yield. A negative effect for this interaction was observed in Venado Tuer in 2009, for the 5009 NA range, where, despite higher water availability, yield was lower. Based on 2008 data in Sancti Spirit, NA 5009 variety, which showed a higher initial rate of root elongation, equal water availability throughout the cycle, and higher yield, emerged as hypotheses for future studies of the differences among these genotypes in root density at different depths, which made this variety more efficient in the use of water when it was most limited.

\section{References}

[1] Bergkamp, G. (1996) Mediterranean Ecosystems. Hierarchical Organization and Degradation. Cip-Gegevens Koninklije Bibliotheek, Den Haag, 238 p.

[2] Fitzjohn, C., Ternan, J.L. and Willians, A.G. (1998) Soil Moisture Variability in a Semi-Arid Gully Catchment: Implications for Runoff and Erosion Control. Catena, 32, 55-70. http://dx.doi.org/10.1016/S0341-8162(97)00045-3

[3] Gómez Plaza, A. (2000) Variabilidad espacio-temporal del contenido dehumedad del suelo en una zona mediterránea semiárida (Space-Time Variability of Soil Humidity Content in a Semiarid Mediterranean Area). Efectos de las condiciones antecedentes en la respuesta hidrológica (Effects of Previous Conditions in the Hidrologic Answer). Tesis Doctoral, (Final Paper) ETSI de Montes, Madrid, 185 p.

[4] Bertolini, D., Cassettari, M., Salvetti, G., Tombari, E. and Veronesi, S. (1990) Time Domain Reflectrometry to Study the Dielectric Properties of Liquids: Some Problems and Solutions. American Institute of Physics Review of Scientific 
Instruments, 61, 450-456.

[5] Dalton, F.N. (1992) Development of Time-Domain-Reflectometry for Measuring Soil Water Content and Bulk Soil Electrical Conductivity. In Advances in Measurement of Soil Physical Properties: Bringing Theory into Practice. Soil Sci. Soc. Am. Special Pub., 143-167.

[6] García, H., Mendoza, R. and Pomar, M.C. (2008) Deficit and Excess of Soil Water Impact on Plant Growth of Lotus tenuis by Affecting Nutrient Uptake and Arbuscular Mycorrhizal Symbiosis. Plant Soil, 304, 117-131. http://dx.doi.org/10.1007/s11104-007-9526-8

[7] Mendoza, R., Escudero, V.I. and García, I. (2005) Plant Growth, Nutrient Acquisition and Mycorrhizal Symbioses of a Water Logging Tolerant Legume (Lotus glaber Mill.) in a Saline-Sodic Soil. Plant Soil, 275, 305-315. http://dx.doi.org/10.1007/s11104-005-2501-3

[8] Dardanelli, J., De La Casa, A.C. and Ateca, M.R. (1991) Validación del balance hidrológico versátil para la sucesión sorgo soja bajo dos sistemas de labranza (Validation of Versatile Hydrologic Balance for Sorghum Soybean Succession under Two Farming Systems). Revista agropecuaria de Manfredi y Marcos Juárez, 7, 20-29.

[9] Bonel, B., Costanzo, M., Torezani, M. and Gómez, E. (2005) Efecto del manejo de un cultivo de soja en siembra directa sobre el microambiente edáfico y su incidencia sobre la modulación (Effect of Soybean Crop Management in Tillage System on Edaphic Microenvironment and Its Impact on Modulation). RIA, 34, 39-58.

[10] Ateca, M.R., Sereno, R. and Apezteguía, H. (2001) Zonificación de una superficie cultivada con soja según aspectos fonométricos y consumo de agua del suelo (Zoning of a Surface Farmed with Soybean Further to Phonometric Aspects and Soil Water Consumption). Revista Brasileira de Meteorologia, 9, 111-116.

[11] Pantaleone, V.R., Rebetzke, G.J., Burton, J.W., Carter Jr., T.E. and Israel, D.W. (1999) Soybean PI 416937 Root System Contributes to Biomass Accumulation in Reciprocal Grafts. Agronomy Journal, 91, 840-844. http://dx.doi.org/10.2134/agronj1999.915840x

[12] Delgado, R., Castro, L., Cabrera de Bisbal, E., Mújica, M.J., Caniche, S., Navarro, L. and Noguera, I. (2008) Relationship between Some Soil Physical Properties and Characteristics of the Root System of Maize Grown in a fluventis Haplustoll Soil of Maracay, Venezuela. Agronomía Trop, 58, 245-255.

[13] Besharat, S., Nazemi, A.H. and Sadraddini, A.A. (2009) Parametric Modeling of Root Length Density and Root Water Uptake in Unsaturated Soil. Turkish Journal of Agriculture and Forestry, 34, 439-449.

[14] ASTM (2003) Standard Test Methods for Determination of the Soil Water Characteristics Curve for Desorption Using a Hanging Column, Pressure Extractor, Chilled Mirror Hygrometer, and/or Centrifuge. Annual Book of ASTM Standards 04

[15] Di Rienzo, J.A., Casanoves, F., Balzarini, M.G., Gonzalez, L., Tablada, M. and Robledo, C.W. InfoStat versión 2011. Grupo InfoStat, FCA, Universidad Nacional de Córdoba, Argentina.

[16] Zuur, A.F., Ieno, E.N., Walker, N.J., Saveliev, A.A. and Smith, G.M. (2009) Mixed Effects Models and Extensions in Ecology with R. Springer Science Business Media, LLC, 563 p. http://dx.doi.org/10.1007/978-0-387-87458-6 